\title{
Design and simulation of a new PCM heat exchanger for domestic hot water and air temperature control
}

\author{
Jacques Robadey,*, Simon Rime ${ }^{1}$, and Dominique Voide ${ }^{1}$ \\ ${ }^{1}$ University of Applied Science of Western Switzerland, 1700 Fribourg, Switzerland
}

\begin{abstract}
Based on previous experiences which have proven the efficiency of PCM heat exchangers for air temperature control, we designed and simulated new PCM heat exchanger structures made of multiple PCM layers sandwiched between loading and discharge layers. By circulating air or water in the discharge circuit, these heat exchangers can be used for heating air or water, respectively. For both use cases, a threedimensional analysis of the phase change and calculations of the charge/discharge powers were performed for the fusion and solidification processes. We obtained heating discharge powers $\geq 2.6 \mathrm{~kW} / \mathrm{m}^{3}$ for 8 hours for air and $\geq 65 \mathrm{~kW} / \mathrm{m}^{3}$ for 13 minutes for water with a respective total storage capacity of $28 \mathrm{kWh} / \mathrm{m}^{3}$ and $37 \mathrm{kWh} / \mathrm{m}^{3}$. The heat extraction of air and water flows and their time dependence are discussed according to the percentage of liquid PCM and the temperature profile of the discharge flow inside the heat exchanger.
\end{abstract}

\section{Introduction}

If the use of renewable energy can increase building energy autonomy, it still faces a major problem: the time dephasing between peak energy production and thermal needs. As thermal needs correspond to about $80 \%$ of building energy consumption in central and northern Europe, thermal storage could be the ideal solution to increase the self-consumption of buildings equipped with renewable energy [1-3].

In that respect, Phase Change Materials (PCM) have been successfully used for heat storage and in building temperature stabilization. In most cases it is integrated in building walls, floors or ceilings that can smooth day and night temperature fluctuations [4]. However, this "passive" way of using PCM does not allow an active control of the storage process and ondemand heat discharges are not possible.

We propose a new system based on PCM layer(s) placed between two circuits: one for loading and the other for discharging, which makes on-demand activation of the charge and discharge processes possible. Such a system was previously developed with a $4 \mathrm{~m}^{3}$ test bench, which was repeatedly loaded and unloaded to study its thermal properties $[5,6]$. This heat exchanger with thermal storage was however dedicated to air temperature control and could not be used for domestic hot water. We propose in this paper a new PCM heat exchanger structure that can either be used for air temperature control or for domestic hot water, and that uses its own structure to macro-encapsulate the PCM.

\section{PCM structures for air temperature control and domestic hot water}

For building applications phase change materials must be encapsulated to prevent leakage and increase heat transfer rate. Two solutions are available for this purpose: microencapsulation where tiny PCM particles are embedded in a protective coating and macroencapsulation with PCM containers usually larger than $1 \mathrm{~cm}$ [4]. The choice of encapsulation depends on PCM use. For integration in the working fluid of the heating circuit, microencapsulated PCM slurry could be used. High heat transfer coefficients have been reported [7, 8], but large PCM slurry thermal storage tanks are required. In the case of passive thermal storage, integration of microencapsulated PCM in concrete, plaster wallboard, ceiling and floor is ideal $[4,9]$. The lower PCM content is compensated by the large size of the storage elements. However, if the PCM must be integrated in a smaller volume such as small size heat exchangers, a macroencapsulation within the exchanger is advantageous.

This is the case if standard radiators are replaced by PCM heat exchangers, e.g. in the case of renovation. We propose such a system with a new air/PCM/water heat exchanger of $1.5 \mathrm{~m} \times 0.3 \mathrm{~m} \times 0.5 \mathrm{~m}(\mathrm{~L}, \mathrm{~W}, \mathrm{H})$. A horizontal cut of the structure is illustrated in Figure 1. It consists of vertical layers with a loading fluid circuit surrounded on both sides by PCM layers and discharge fluid layers. This layering is repeated five times. An aluminum structure separating the different layers allows the macro-encapsulation of the PCM and also increases the heat extraction surface between PCM and both loading and discharge layers.

\footnotetext{
*Jacques Robadey, Simon Rime and Dominique Voide, Corresponding author: jacques.robadey@hefr.ch
} 


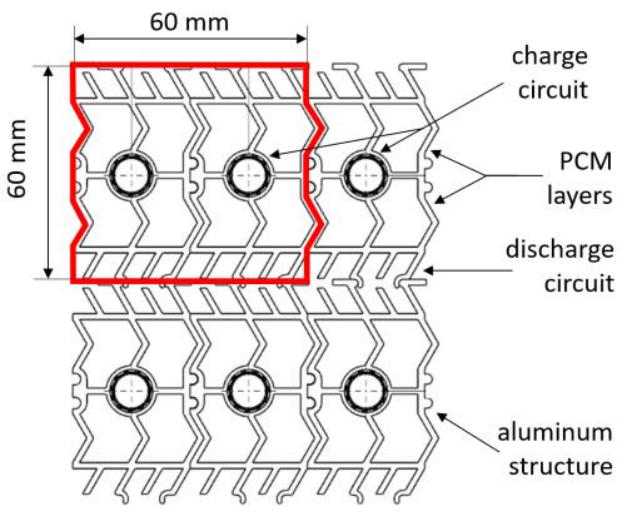

Fig. 1. Horizontal cut of the proposed PCM heat exchanger. The water charge circuit is surrounded by PCM. In the discharge circuit an air or water flow is used for air temperature control and hot water generation, respectively. The bold line delimits the cell used for the simulations.

The proposed thermal storage structure could be either used for domestic hot water or for air temperature control. For hot water the discharge circuit is a water circuit instead of an air circuit and the PCM used has a melting temperature of $43^{\circ} \mathrm{C}$ instead of $23^{\circ}$. The resulting device becomes a water/PCM/water heat exchanger. Note that for both purposes a PCM with a melting temperature of $43^{\circ} \mathrm{C}$ could be used. This would be an interesting alternative if the loading source comes from solar thermal panels. However, in the case of a loading heat pump, such a high temperature is not optimal for air temperature control and PCMs of about $23^{\circ} \mathrm{C}$ are preferred.

While the thermal storage device for hot water is dedicated to an entire building, the storage devices for air temperature control are dedicated to one room or less. The size of the PCM heat exchangers must therefore be adapted but the basic structure displayed in Figure 1 will remain the same.

\section{Simulations of PCM charge and discharge for hot water and air temperature control}

We performed charge and discharge simulations of the PCM heat exchanger for the two use cases of air temperature control and hot water production using the ANSYS Fluent 17.2 Computational Fluid Dynamic modelling tool. The simulation was applied to the cell shown in Figure 1. For the purpose of the simulation, this cell was divided in a mosaic of smaller triangular cells that were made of the same material such as air, aluminum, PCM or water and represent only a small portion of that material. Since the basic cell is symmetrical and repeats on all sides, the boundary condition defining the same temperature profile along the right and left sides and along the bottom and top sides has been introduced. To our knowledge, this type of analysis comparing the charge and discharge processes of an air/PCM/water and a water/PCM/water heat exchanger with an identical structure has not yet been carried out.

\subsection{Charge process}

The charge was performed by a $31 / \mathrm{min}$ water flow of $35^{\circ} \mathrm{C}$ for air temperature control and of $50^{\circ} \mathrm{C}$ for domestic hot water, flowing through a heat exchanger of a height of $0.5 \mathrm{~m}$. The PCMs were PureTemp 23 and Rubitherm RT44HC with fusion temperatures of $23^{\circ} \mathrm{C}$ and $43^{\circ} \mathrm{C}$ and heat storage capacities of $201 \mathrm{~kJ} / \mathrm{kg}$ and $250 \mathrm{~kJ} / \mathrm{kg}$, respectively. The increase of the PCM liquid phase during the charge process is illustrated in Figure 2.

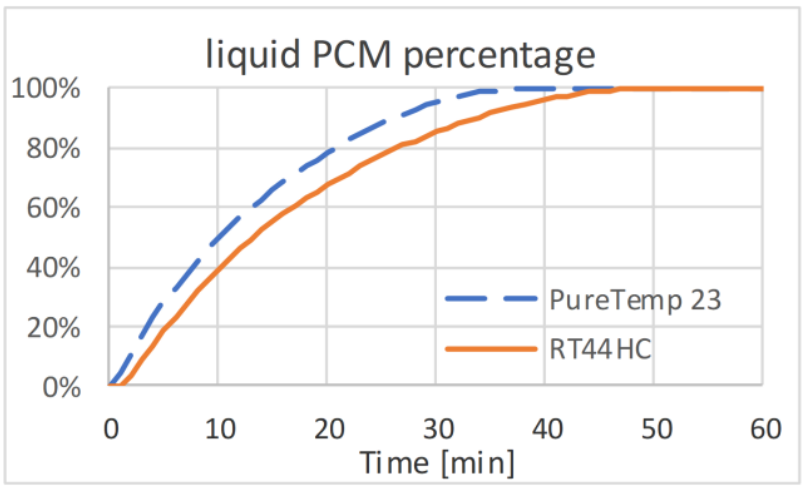

Fig. 2. Percentage of the liquid phase during loading for the PCMs used for air temperature control (dashed line) and hot water (continuous line).

The slower fusion of the RT44HC PCM shown in Figure2 is due to its larger heat storage capacity, the larger temperature increase between its starting temperature and the fusion temperature, as well as the lower difference between the PCM fusion temperature and the loading circuit temperature $\left(7^{\circ} \mathrm{C}\right.$ instead of $12^{\circ} \mathrm{C}$ for the PureTemp23). Despite this difference in loading speed, the behavior of both PCMs was similar.

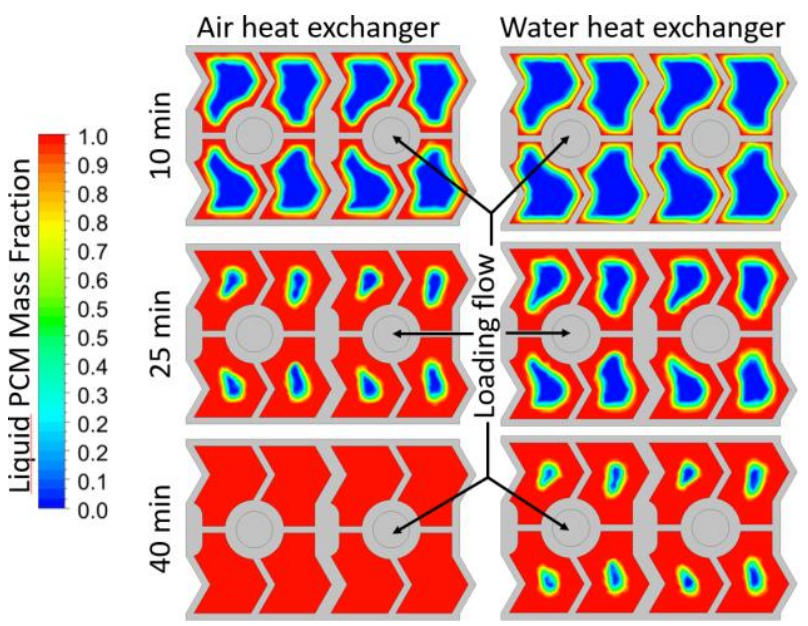

Fig. 3. Proportion of liquid PCM after 10, 25 and 40 min of charge just before the exchanger exit. The starting temperature is $22^{\circ} \mathrm{C}$ and $30^{\circ} \mathrm{C}$ for $\mathrm{PCM}$ melting temperature of $23^{\circ} \mathrm{C}$ and $43^{\circ} \mathrm{C}$ for the air and water heat exchanger, respectively. 
This similar behavior is also visible in Figure 3 illustrating the evolution of the fusion process during 40 minutes of charge for both heat exchangers. We only observed a slightly slower fusion process for the water heat exchanger that contains the RT44HC PCM.

\subsection{Discharge process}

The discharge was carried out by air and water circulating at $0.75 \mathrm{l} / \mathrm{min}$ through a $0.5 \mathrm{~m}$ and $2 \mathrm{~m}$ high heat exchanger cell (Figure 1), respectively. In the first case the chosen incoming air temperature is $11^{\circ} \mathrm{C}$ as it is considered to be the fresh air from the air renewal system. For the hot water case the chosen water temperature was also $11^{\circ} \mathrm{C}$. Note that the PCM temperature at the start of the discharge was at the melting temperatures of $23^{\circ} \mathrm{C}$ and $43^{\circ} \mathrm{C}$, respectively.
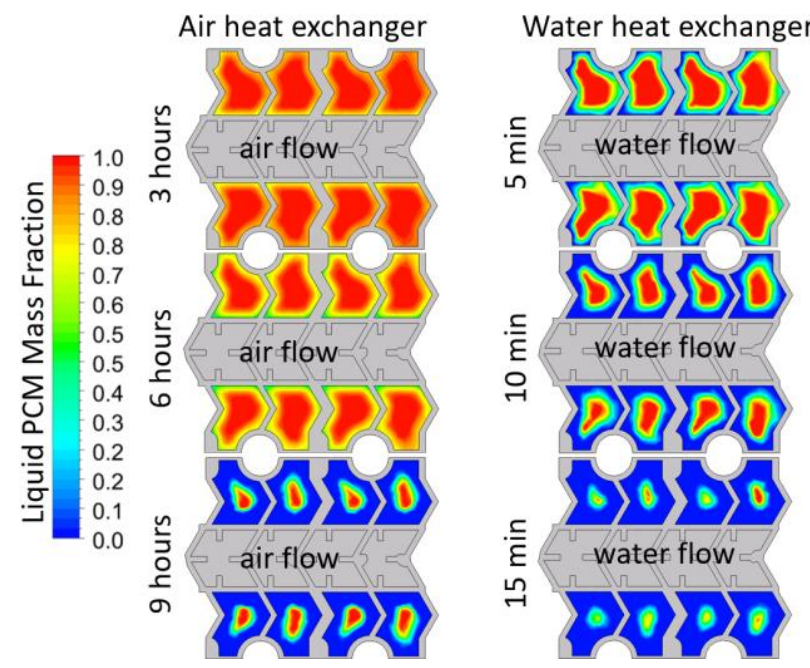

Fig. 4. Evolution of the liquid PCM proportion after discharges of 3, 6 and 9 hours for air heating and of 5,10 and 15 min for water heating. Discharge and PCM layers are shown.

Figure 4 shows the gradual reduction of the PCM liquid phase caused by the flow of fresh air and water through the grey area just before the heat exchanger exit. One can observe a discharge about 40 times faster for heating water than for heating air. This is mainly due to the large difference between the volumetric heat capacity of air and water.

Figures 6 and 7 describe the heating power of one cell as a function of time for both air and water heating. As a heat exchanger of $1.5 \mathrm{~m} \times 0.3 \mathrm{~m} \times 0.5 \mathrm{~m}$ is made of 125 cells, the simulation indicates that an air heating power larger than $600 \mathrm{~W}$ can be maintained for 8 hours. By considering the dimensions of the exchanger, it corresponds to heating power densities of $2.6 \mathrm{~kW} / \mathrm{m}^{3}$ with a storage capacity of $28 \mathrm{kWh} / \mathrm{m}^{3}$.

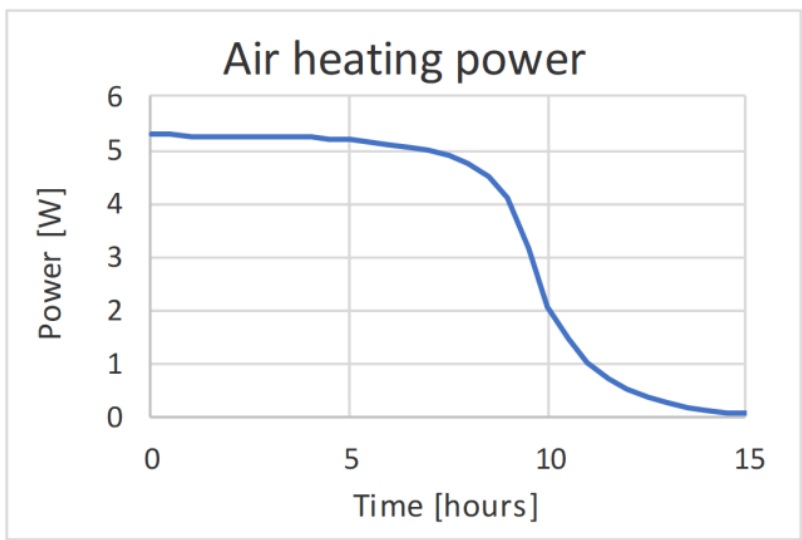

Fig. 5. Discharge power of one cell of the air-PCM-water heat exchanger.

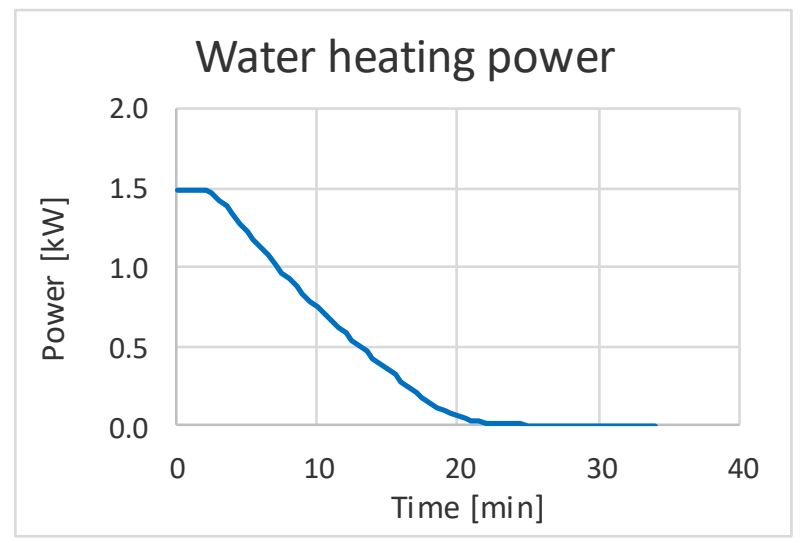

Fig. 6. Discharge power of one cell of the water-PCM-water heat exchanger.

The water heating power is much larger due to a better heat transfer and a heat exchanger height of $2 \mathrm{~m}$. By using 50 cells with a dimension of $0.6 \mathrm{~m} \times 0.3 \mathrm{~m} \times 2 \mathrm{~m}$ $(\mathrm{L}, \mathrm{W}, \mathrm{H})$, a heating power $\geq 23.5 \mathrm{~kW}$ could be achieved for about $13 \mathrm{~min}$. This corresponds to $65 \mathrm{~kW} / \mathrm{m}^{3}$ with a storage capacity of $37 \mathrm{kWh} / \mathrm{m}^{3}$.

The constant reduction of the power only observed for the water discharge can be explained by the different fluid temperature profile in the heat exchanger. At the start of the discharge, the air flow reaches its maximal temperature (which is close to the PCM fusion temperature) before leaving the heat exchanger. The point where the maximal temperature is reached moves toward the exit of the exchanger during the discharge. As displayed in Figure 7, after one hour of discharge, the air flow temperature reaches its maximum after approximatively $35 \mathrm{~cm}$ and remains stable thereafter. After 5 hours the maximal temperature is reached at the end of the exchanger and the power, displayed in Figure 5 , begins to drop. In the case of the water heat exchanger illustrated in Figure 8, the flow reaches its maximal temperature before the exit of the exchanger only during the first 3 minutes. As displayed in Figure 6, the power remains constant during that time and decreases continuously afterwards. 


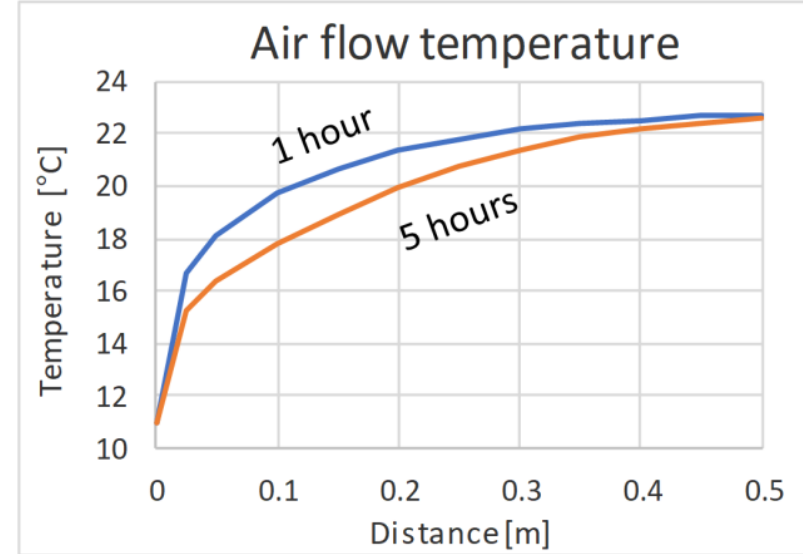

Fig. 7. Air flow temperature profile after one and five hours of discharge.

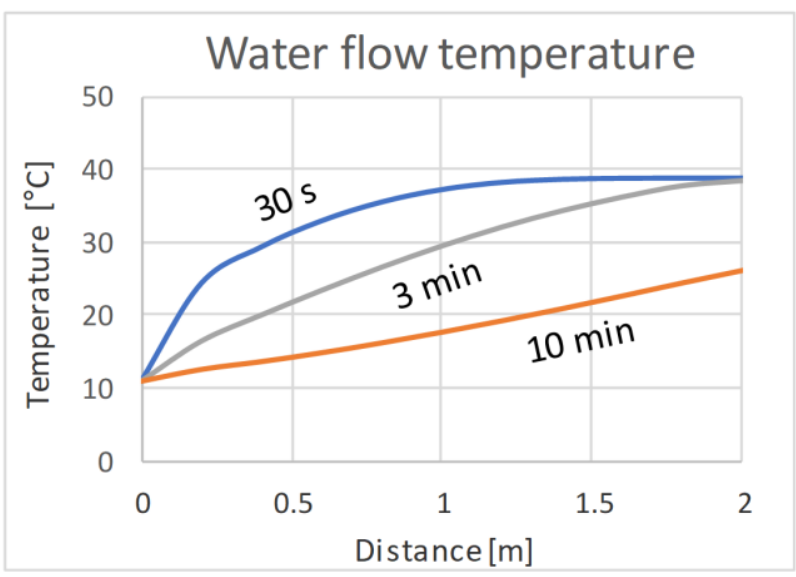

Fig. 8. Water flow temperature profile after different discharge times.

\section{Results discussion}

The proposed structure can be either used for air or for water heating but the efficiency of the water discharge rapidly decreases even for a heat exchanger height of 2 meters. As the power is larger than $20 \mathrm{~kW}$ and the total thermal storage is $13 \mathrm{kWh}$, it however satisfies the hot water demand of a single-family home.

The simulated PCM air heat exchanger showed a discharge power of $600 \mathrm{~W}$ for dimensions of $1.5 \mathrm{~m} \times 0.3 \mathrm{~m} \times 0.5 \mathrm{~m}$ that lasts for 8 hours with a storage capacity of $6.3 \mathrm{kWh}$. The too low power can be explained by the structure not optimized for air flows. A larger exchange surface between PCM and air layers is necessary, which can be achieved by adding new air channels in the PCM layers. A higher PCM fusion temperature and a slightly larger heat exchanger would also increase its power. By doubling the power of such heat exchangers and integrating them into the rooms of a well-insulated building $\left(\mathrm{U} \leq 0.2 \mathrm{~W} / \mathrm{m}^{2} \mathrm{~K}\right)$, the discharge heating power would be sufficient for temperatures down to $-5^{\circ} \mathrm{C}$ with a storage capacity allowing a thermal energy autonomy of 1.5 day [6].

If these simulations are very promising, they must still be verified by real experiments. For this purpose, two test benches with a cross section of $0.3 \mathrm{~m} \times 0.3 \mathrm{~m}$ and heights of $0.5 \mathrm{~m}$ and $2 \mathrm{~m}$ are currently under construction.
Air and water heat exchangers will be realized by integrating PCMs of melting temperatures of $23^{\circ} \mathrm{C}$ and $43^{\circ} \mathrm{C}$ close to the air and water discharge circuit, respectively. The validity of the simulations will be checked with the measurements of the charge and discharge powers for both test benches.

Note that if sufficient heating powers could be obtained with PCMs with a melting temperature of $23^{\circ} \mathrm{C}$, they could also be used for cooling. As we proposed to use air renewal to ventilate the PCM heat exchanger, such a system could perform heating, cooling, heat and cold storage as well as air renewal. This opens up new perspectives in the field of heating, ventilation and airconditioning for new and renovated buildings.

\section{Conclusion}

The discharge of Air/PCM/water heat exchangers of $0.35 \mathrm{~m}^{3}$ located in each room of a well-insulated building can heat it sufficiently down to $-5^{\circ} \mathrm{C}$. To this end, the proposed structure must however be further optimized by the addition of new air channels. Water PCM heat exchangers of the same size can also be sufficient for individual houses. The efficiency predicted by the simulations must still be verified by in situ experiments and costs calculations must be made comparing the PCM devices with large water tanks.

The relatively low temperature required to load the air PCM heat exchanger makes the use of heat pumps advantageous. Interestingly, the PCM heat exchanger for domestic hot water has the advantage of heating cold water directly before consumption. This could prevent the occurrence of salmonella without necessitating high temperature water heating. The use of PCM heat exchangers is therefore promising for both air temperature control and hot water production. However, the same structure cannot be used optimally for both applications and requires adaptations for each.

The authors would like to thank the "Innosuisse" programme that financed the research work described in this paper together with the companies: WT AG, Sottas Building SA, DCA SA Architectes associés and Amstein + Walthert Genève SA.

\section{References}

1. L. Cao, D. Su, Y. Tang, G. Fang, F. Tang, Renew. and Sustain. Energy Rev. 48, 500 (2015)

2. B. Akhmetov, A.G. Georgiev, A. Kaltayev, A.A. Dzhomartov, R. Popov, M.S. Tungatarova, Bulg. Chem. Commun. 48, Spec. Issue $E, 31-40$ (2016)

3. J. Robadey, J. Phys. Conf. Ser. 1343, 012170 (2019)

4. L.F Cabeza, A. Castell, C. Barreneche, A. Gracia, A.I. Fernandez, Renew. and Sustain. Energy Rev. 15, 1675-1695 (2011) 
5. R. Wegmüller, G. Magnin, J. Robadey, E.L. Niederhauser, Proc. 5th int. conf Renew. Energy: Generation and Applications, 154-157 (2018)

6. J. Robadey, E.L. Niederhauser, A. Boss, G. Magnin, R. Wegmüller, Proc. 15th Symposium Energieinnovation, Graz, Austria (2018)

7. Y.Yamagishi, H. Takeuchi, A.T. Pyatenko, N. Kayukawa, AIChE Journal 45, 4 (1999)

8. Y. Guo, X. Zhang, L. Yang, C. Xu, X. Du, Energies 2017, 10, 1662 (2017)

9. A.M. Khudhair, M. M. Farid, Energy Convers. and Manag. 45, 263-275 (2004) 